\title{
From Presences to Linked Influences Within Communities of Inquiry
}

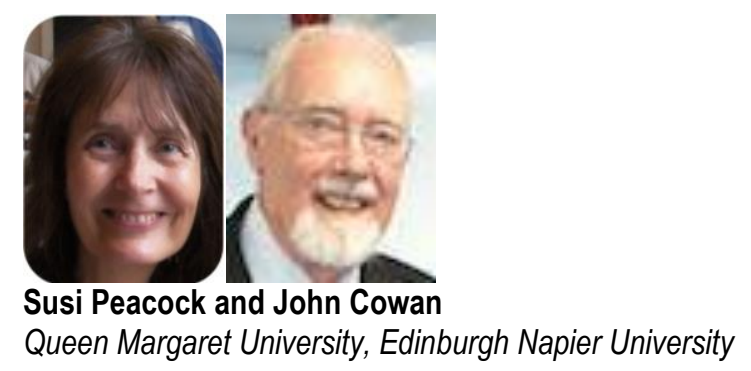

\begin{abstract}
Much research has identified and confirmed the core elements of the well-known Community of Inquiry Framework (CoIF): Social, Cognitive and Teaching Presence (Garrison, 2011). The overlap of these Presences, their definitions and roles, and their subsequent impact on the educational experience, has received less attention. This article is prompted by the acceptance of that omission (Garrison, Anderson, \& Archer, 2010). It proposes enrichment to the Framework, by entitling the overlapping spaces uniting pairs of Presences as "Influences." These three spaces, linking pairings of Social, Teaching, and Cognitive Presences, can be labelled as "trusting," "meaning-making," and "deepening understanding." Their contribution to the educational experience is to address constructively some of the challenges of online learning, including learner isolation, limited learner experience of collaborative group work and underdeveloped higher-level abilities. For these purposes we also envisage "cognitive maps" as supporting learners to assess progress to date and identify pathways forward (Garrison \& Akyol, 2013). Such maps, developed by a course team, describe the territory that learners may wish to explore, signpost possible activities, and encourage the development of cognitive and interpersonal abilities required for online learning. We hope that considering the Influences may also assist tutor conceptualisations of online community-based learning. Our proposals call on both learners and tutors to conceive of the Presences and Influences as working together, in unison, to enhance the educational experience whilst fostering deep learning. Our suggestions are presented to stimulate scholarly debate about the potential of these interwoven sections, constructively extending the Framework.
\end{abstract}

Keywords: Community of inquiry, presences, influences, cognitive maps, tutoring, deep learning 


\section{Introduction}

Over the last two decades, continuing interest in online higher education has resulted in a rapid growth in its number of programmes and learners, leading some to assert that it has become the "... preferred or 'new normal' mode of study throughout the world" (Brown, 2015, p. 1). There has, however, been an ambivalent response to these innovative developments with many, including employers, doubting the value and legitimacy of accredited online learning especially in view of its high attrition rates, and low levels of learner attainment and progression (Allen \& Seaman, 2013; (Columbaro \& Monaghan, 2009). Indeed, some will question if learners are ready, and prepared, for the transition from more traditional, didactic face-to-face learning experiences to online activity (Akyol, 2013). Although technologies supporting online environments have been quickly and readily implemented for learners, their understandings of the abilities required of them to flourish in such environments are limited (Cleveland-Innes \& Campbell, 2012), leading some to question if deep learning can be nurtured in online programmes.

Tutors, too, are concerned by this new environment, requiring them to be subject, pedagogical, and technological experts, turning the ". . . computer screen into a window so that students feel and behave as if they are working together with a group of peers" (Rovai, 2002, p. 331). Many tutors have deeply held beliefs about learning, teaching and assessment that are often disrupted when moving to online environments. Such disturbances may be linked with their preference for face-to-face teaching and/or their belief of its superiority to online learning (O'Shea, Stone, \& Delahunty, 2015). Thus, in many cases, tutors take the known (face-to-face) as their starting point when developing online learning, being reluctant to change and/or lose their familiar face-to-face practices. Such approaches may result in less than ideal online environments with learners failing to engage in activities that should foster deep learning.

Tutors should have and use models and frameworks to guide and inform their thinking, planning, and designing for online learning. This article reports outcomes of a primarily theoretical interrogation of one of the most prominent and cited models of online learning: the Community of Inquiry Framework (CoIF). This model features the three well-regarded areas termed Presences. In reviewing our experiences of student learning within community activities, we gradually found it persuasive to attribute students' learning and development within a CoIF to activity originating from the overlapping of two Presences, according to what we are here calling Influences. We have not sought counter-examples. However, the empirical examples available to us, including some beyond those specifically cited herein, first generated and then were consistent with this emerging theoretical perception, and encouraged us to proceed.

We have departed in several ways from the nomenclature which is currently favoured in published papers relating to the CoIF. There are two distinct reasons for our changes. The first is our background in the European higher education sector. Following the students' revolts in mainland Europe in 1968, initiatives focusing upon student-managed learning and project-orientation emerged. This emphasis, albeit in face-to-face situations, has much in common with the rationale for studying in online communities of inquiry. In particular, such initiatives moved towards the well-developed concepts and practices that European academics generally refer to as tutoring and facilitation and away from more authoritarian approaches to teaching. We hope that our decision to favour these terms will not alienate or confuse any of our readers. 
We have also individually renamed the three overlap areas with which our paper is concerned. We have made these changes to sharpen the focus and to define more precisely what, in our experience, occurs in these areas of activity. We trust that readers with a long-standing commitment to the current titles will be prepared to accept our suggestions, at least until they have explored the implications of placing stress on these Influences. In our defence, we remind readers who are familiar with the CoIF literature that Garrison has not been averse to renaming the areas in question.

\section{The Community of Inquiry Framework}

Activity in collaborative learning online is frequently described in terms of a Community of Inquiry (CoI), as outlined by Garrison in his seminal work (2011). Such communities are based upon the premise that "Learning in an educational context is a social enterprise" - socially worthwhile and personally meaningful (Garrison, 2013, p. 2).

The individual learner, reflecting the constructivist roots of this approach, is responsible for initial meaning-making from new experiences by building upon, and integrating, previous knowledge and experiences. Learners then check emergent understandings through social interactions in the community where members of the ". . . community challenge beliefs and suggest alternative perspectives for exploration” (Garrison, 2011, p. 43). Learning communities should, in some cases, provide intellectual challenge through dialogic debate, thus enabling learners to go beyond themselves in terms of their depth and breadth of understanding and so into their zones of proximal development (Harasim, 2012). For the community of learners, the outcome or "artefact" of the collaborative endeavour is mutual understanding and the construction and extension of collective knowledge which, Garrison (2013) asserts, may in the longer term, contribute to societal knowledge.

The development and organisation of online communities depend upon a teaching team consisting of subject experts and support staff such as librarians and learning technologists, collaboratively preparing an online environment. A "cognitive map" may be developed, and provided to assist learners in the planning of their studies, and helping them to identify where they have reached at any point in time, where they could go next, and how they might progress (Garrison \& Akyol, 2013). Such maps should inform the development of much needed learner abilities, both cognitive and interpersonal; for example, learners often have limited notions of the rigour and depth required for critical thinking (Parkes, Stein, \& Reading, 2015). Materials explaining how communities could assist learners in going beyond themselves and well into their zone of proximal development (Nicholl, 1998) are an essential resource as students seek to find and make meaning during their ongoing studies. Learners new to the online environment need early help in understanding why it is ". . . worth investing time and energy into learning these new ways of working: becoming part of an academic community" (Baxter, 2012, p. 116). Short videos of learners discussing why they became active participants in a community, rather than feeling isolated individuals in pursuit of their own individual knowledge acquisition, could be shared (Sfard, 1998).

Nurturing the educational experience at the heart of the Community of Inquiry Framework (Figure 1) are three prominent areas, commonly named "Presences," which according to the American Centre for Teaching and Learning (n.d.) are critical to a successful online learning environment. It is with these 
important aspects of the Framework, and their contribution to learning and development, that our paper is concerned.

\section{The Presences}



Figure 1. Community of Inquiry Framework (2011) describing each Presence in turn. Adapted from Garrison, D. R., (2011). E-learning in the $21^{\text {st }}$ Century (2 ${ }^{\text {nd }}$ ed.). New York: Routledge.

\section{Cognitive Presence (CP)}

Cognitive Presence (CP) encompasses the extent that participants in a CoI are able to construct and confirm meaning by engaging in sustained individual and group dialogue and reflection (Garrison, Anderson, \& Archer, 2001). We envisage $\mathrm{CP}$ as including a broad range of cognitive activities involving critical thinking, together with related processes such as reasoning, evaluation, judgement, creativity, reflection, imagination, and deliberation-for all of these together will ultimately contribute to worthwhile learning. We consider reflection in $\mathrm{CP}$ as distinct from critical thinking. We also consider critical thinking to be a cognitive activity involving evaluative scrutiny of thoughts, analysis, synthesis, and judgements leading to reasoned outcomes. It requires thinking clearly and independently about the reasoning behind what to do or what we believe. Reflection, in contrast, is a sophisticated form of thinking in which self-questioning learners engage in unearthing and consolidating deeper personal meanings and understandings. It requires learners to question their frames of reference, the nature of their own knowledge, and the process of learning. Although the two concepts are closely related cognitively, neither is a sub-set of the other (Peacock, 2015). 


\section{Social Presence (SP)}

Social Presence (SP) refers to the engagement of all participants in a CoI in order ". . . to identify with the group or course of study, communicate purposefully in a trusting environment and develop personal and affective relationships progressively by way of projecting their personality" (Garrison, 2011, p. 34). Through open communications learners gain a sense of being connected to, and engaging with, other sentient beings who have a history, emotions, and a genuine concern for others in the community. Thus, ideally, all members of the community are actively listening and prepared to respond to others' social communications. Being socially confident enables learners to express themselves freely, engage in group discussions, and develop a sense of belonging to the group and its academic goals.

\section{Tutoring Presence (TP)}

We have re-named the third Presence as Tutoring Presence to be compatible with student-centred learning (SCL) to which much of our practice and cited examples are committed. This stance also aligns more closely with Lipman's (2003) conceptualisations of the "teacher" in a community of inquiry, which influenced the original thinking behind the CoIF (Dron \& Anderson, 2014).

We subscribe to the view of Akyol and Garrison that this Presence involves the design and facilitation of ". . . social and cognitive presence in a community of inquiry" (2011, p. 185). However, we have become increasingly aware of the need to make a distinction between the "teaching" function associated in the traditional framework with TP, and the ever-present facilitative function required from an engaged, perceptive tutor. Such tutors in SCL assist learners to engage effectively with mastering the various processes demanded of them, whilst not directing the specific actions taken by learners in their exercise of these responsibilities. Thus, the facilitative tutor in SCL concentrates proactively on nurturing the higher level cognitive and interpersonal abilities that are demanded of students by their engagement in the task, but does not interfere with, or offer leads, regarding the execution of that task (Cowan, 2013). From our perspective, such an approach resonates closely with Lipman's work (2003, pp. 18-19).

\section{The Influences}

The purpose of the CoIF is the "development of an appropriate, quality, generic educational experience that is consistent with deep and meaningful approaches to online learning" (Garrison, 2011, p. 50). We now suggest that it is the interweaving of the Presences, rather than the Presences per se, that leads to knowledge construction and personal meaning making. We therefore use the title "Influence" for the interwoven areas in the Model that, we argue, serve to combine Presences in a community's purposeful pursuit of the desired educational experience.

The role of these intersections of the Presences has received relatively little detailed attention to date. Garrison and colleagues admitted in their retrospective review, that ". . . the dynamic relationships among the Presences could have been emphasized to a greater extent" (Garrison et al., 2010, p. 6). Garrison states that much research into the CoIF has focused upon defining (our emphasis) the individual presences rather than the relationship between them (Garrison, 2011, p. 27). Certainly some work has explored relationships between the Presences (Garrison et al., 2010; Shea \& Bidjerano, 2009a). However, contributions to the CoI literature fail to discuss in detail how the Presences 
function in unison, and with what impact. It is with that omission that we are concerned in this paper. We therefore first address each Influence (linking two Presences) in turn, followed by the associated contribution that is made to this Influence by the outstanding Presence.

We have labelled the Influence areas in Figure 2 as "trusting," "collaborative learning," and "deepening understanding." We have carefully chosen these titles to convey to students and tutors as accurately as possible the rigour of the contributions expected from each interweaving of Presences. We envisage each Influence as primarily depending upon the purposeful harnessing of the joint potential found within two Presences, with appropriate support from the third Presence. We now outline each of these Influences, giving attention to their potential role in the educational experience.

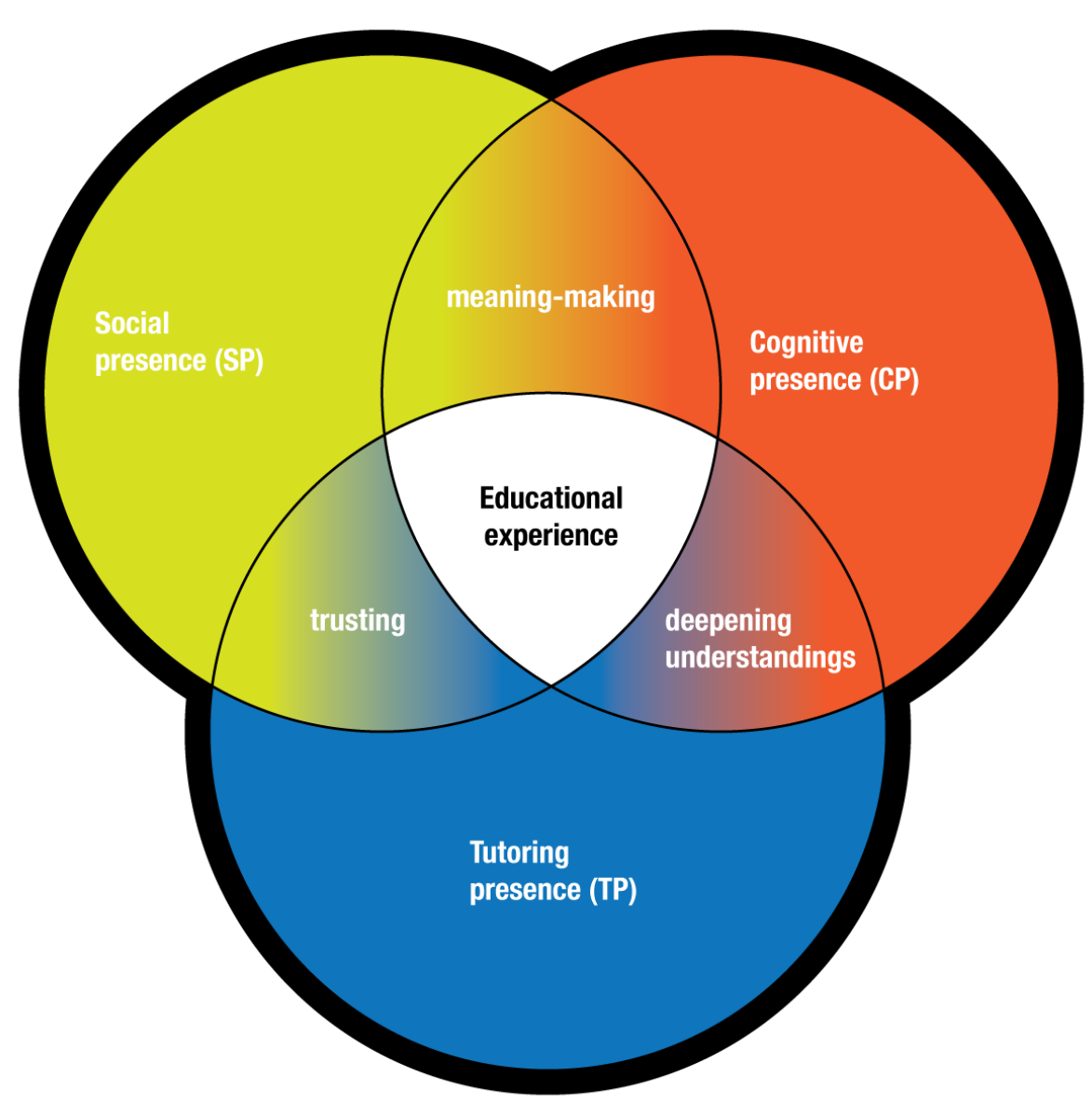

Figure 2. Community of Inquiry model indicating presences and influences.

\section{Trusting: The Influence Linking TP and SP}


We have found Tutoring Presence (TP) interacts positively with Social Presence (SP) at every stage in the lives of the communities we have studied (Peacock, 2015). It is important to any CoI to set the tone of openness, fairness, safety, and debate, and above all to nurture self-efficacy to lead individuals and communities to go beyond what they might judge to be their potential. This activity certainly extends beyond setting an (initial) climate. The foundation upon which the key behaviours are founded is trust among the community and with the tutor. It is through this relationship, for example, that selfefficacy and confidence are nurtured and fulfilled (Peacock, et al., 2010). So, by calling this first Influence "Trusting," we deliberately echo the strong emphasis throughout the writings of Rogers (1980) and Brookfield (1990) on the importance of trust in all learning relationships. Learners need to feel safe and comfortable when engaging in dialogic debates that can occur free of intimidation, and call for truly open exchanges, with a trusting expectation of frank and appropriate responses (Akyol, 2013). Mutual trust binds together all who are involved in a CoI for effective interaction.

The pro-active contribution of TP to this Influence is important in selecting and promoting processes that develop a trusting sense of belonging. We identify four distinct tutoring roles that are particularly linked to learners' feelings of comfort in online discussions, their development of social confidence, and their sense of belonging to the community. These have been identified as a major influence on the effectiveness of their consequent engagement with Cognitive Presence (Shea \& Bidjerano, 2009b).

The first of these tutoring roles addresses learner comfort in online discussions, the most commonly used vehicle for communications in online learning. For many learners, the very nature of posting to an online space of thoughts to be read by unknown peers and tutors is alien, threatening, and impersonal. This often unexpected demand of online learning becomes even more daunting for the learner when the communication tools provided by the institution are cumbersome and difficult compared to the more familiar social network tools such as Facebook. Tutors may wish to encourage familiarity with online discussions through, for instance, the use of ice-breaking activities with learners sharing information by contributing through posting and responding to other learners as discussed in Salmon's model (2006). Through such activities most learners begin to identify with the group, building trust and developing personal relationships. Guides about the purpose of online discussions can also be made available for learners and signposted in the cognitive map.

The second tutoring role focuses upon the initial nurturing and then the ongoing development of learners' skills and inclination to project SP. It includes fostering a disposition amongst learners to read and understand the cues embedded in the text-based messages of others. A peer typified this in a student's account in Kehrwald's work of such an experience:

Sometimes when I post a comment that somehow doesn't come to grips with the real message that I am delivering, someone else looks past clumsy language and picks out the guts of what I am saying. That shows understanding, not just of the words, but of the person who said them. (Tim, distance learner, Kehrwald, 2008, p. 98)

Usually learners' preconceived notions of SP will, in turn, affect the ability of individuals to make themselves known to their peers as real social actors in the online environment. The tutor's role here is to encourage learners to empathically project their personal characteristics into their joint pursuit of worthwhile learning outcomes, acknowledging that: 
... students perceiving the greatest [social] presence of others in online discussions also consistently project more of their own presence into them, and that they did this in specific ways: by sharing something of themselves with their classmates, by viewing their class as a community, and by acknowledging and building on the responses of peers. (Swan \& Shih, 2005, p.124)

A third pivotal role for the tutor is to encourage learners to use available cognitive maps, and in due course to devise their own. Tolman (1958) introduced the concept of cognitive maps, based upon his investigations of rats navigating a maze. Cognitive maps in education can be a valuable resource for human learners navigating through unfamiliar learning landscapes. A well-designed map can aid learners to navigate the maze of such landscapes to good purpose, by providing "landmark knowledge" (Li, Chen, \& Yang, 2013). Maps not only show where learners can make their start towards desired progress, they can also indicate the routes learners can use depending on what is, and is not, important to each individual and their community. A map can then be used to record the route taken, including distractions from it. As the community progresses, learners may assemble their own maps to inform their plans for further progress.

The final pivotal role for tutors is preparing learners to cope with the emotional issues arising in online learning (Cleveland-Innes \& Campbell, 2012). Responding to the new and open demands of higher level collaborative learning calls upon individual learners to confront risks of failing, or being seen to have failed, or self-judging themselves to have failed. Many learners report feelings of intimidation when peers appear to have a greater understanding of the concepts being discussed. This was highlighted by one of the students in Cleveland-Innes et al. study (2007) “... I can be intimidated by huge thoughts from bright people" (p.7).

We have found it important to recognise the effect of emotional issues for their vital role in developing, though sometimes hampering, Social Presence (Cowan, 2015). This was illustrated in student responses where online physiotherapy learners valued a virtual social café as a safe place to meet, discuss, and share concerns, and to realise reassuringly that others shared similar worries. As one student stated, "Seeing that other people felt the same as you at certain stages helped a lot" (Peacock \& Hooper, 2007, p. 324).

Still in connection with this tutorial role, we point out that cognitive maps may offer helpful guidance on how students can manage their emotional responses effectively when working online collaboratively. Learners may wish to develop coping mechanisms such as increased awareness and utilisation of the different avenues available for support. Xu, Du, and Fan (2013) conclude that the tutor will ". . . want to promote a culture of help-seeking, encouraging students to learn how to ask for assistance from multiple sources (for example, the instructor, peers and friends) through multiple channels (for example, email, web chat, and video conferencing) when they confront personally challenging tasks and perceive the need for help" (p. 7).

In our experiences, the constructive and deeply trusting relationships that hold peers and tutors intimately together become increasingly important as the work of a community progresses, and as learning deepens (Peacock, 2015; Francis \& Cowan, 2008). Interactions within the CoI will be ineffective unless learners are strongly influenced by, and are confident in, the trust amongst learners and tutor developed between SP and TP, and applied in the context of the engagement in Cognitive Presence (CP). Yet Garrison (2011) seems to disregard this progression, contending that although SP 
is highly desirable and essential in creating a CoI, its purpose and sustenance are often secondary. Accordingly, he has titled this Influence "Setting Climate," implying a preparatory stage in developing an intellectually thriving community (Garrison, 2011, p. 23). However, we have found that our learning communities have only prospered when members have had a strong and developing sense of belonging, especially in the case of postgraduates in professional (Peacock, 2015; Ke, 2010). We expand upon this point under the next Influence.

\section{Meaning-Making: The Influence linking SP and CP}

The linkage between SP and CP is a vital element in the CoI process in contributing effectively to the learning outcomes as members of the Community are facilitated to find and consolidate through their discourses the substance from which their Community can make worthwhile meanings (Peacock \& Hooper, 2007). We have preferred "Meaning-Making" to "Supporting Discourse," emphasising outcome rather than process. Consequently this Influence is identified as building upon and amplifying Garrison's (2011) original titling. Tutors and students are thus encouraged to address both the initial and the ongoing meaning-making that is dependent upon learners working interdependently with content sourced within CP. The depth of consequent learning will thus rely considerably upon a lively SP, supporting constructive interactions within the community with a deepening CP. For collaborative learning to be powerful and effective, learners must want to feel sufficiently confident to ask probing, challenging questions such as "How did you come to that conclusion?" and "How do you know that?"

A particular feature of this Influence is the monitoring of co-cognition, and learners' joint management of opportunities for and impediments to cognition, supported through social communications online (Akyol, 2013). First, learners engage in shared discussions, selecting and setting appropriate challenging goals, reviewing proposed plans and strategies, and considering potential barriers to success. Successive ongoing discussions should then support group review of progress to date, clarification of the activities in hand, and management of tasks (Shea et al., 2012). Throughout such group interactions, learners should consult metaphorical cognitive maps that would them to locate progress to date and inform potential pathways forward, thereby encouraging all members of the community to ask probing questions such as "What other options are there?" or "What would be the implications of that approach?"

Such group interactions provide ideal venues for the honest sharing of the perceived impact, positive or otherwise, of group work on meaning-making and deepening understandings. It is often a source of learner frustration when group work is linked to differing learner aims. High-achieving learners resent the lack of commitment of other group members. Such negativity is exacerbated if all members of the group receive the same mark when they are graded. While similar student frustrations are widely reported in face-to-face group work, the online element appears to strengthen learner negativity (Brindley, Blaschke, \& Walti, 2009; Capdeferro \& Romero 2012; Goold, Craig, \& Coldwell, 2008) and thus Järvenoja and Järvelä (2009, p. 465) argue that the "regulation of emotion, at both the individual and group level, is critical for successful collaboration."

Additional and clear facilitative prompting by tutors to promote cognition, metacognition, and reflection within discussion postings should encourage the development of peers' questioning and defence of others' ideas, as well as the articulation of self and co-regulation (Akyol, 2013). However, as the tutor progressively exercises less responsibility for direction, the increasingly autonomous learners must feel sufficiently safe and comfortable to explore their concerns and frustrations 
collaboratively with their online peers, through an effective SP. Peers should increasingly provide ongoing support in the role of peer-facilitators (McCormick \& Davenport, 2004) helping to alleviate feelings of isolation, frustration, and anxiety, and avoiding such impediments to learning by providing prompt responses that acknowledge and encourage (Xu, Du, \& Fan, 2013).

As already mentioned, we have found that furthering the engagement with $\mathrm{CP}$ for profound learning often depends upon increasingly keen integration within an active SP. This is particularly so in professional online programmes, where learners work collaboratively, discussing at depth with peers their emergent understandings of complex issues arising from their professional activities (Peacock \& Hooper, 2007). Thus we regard SP as on ongoing component of the Influence driving collaborative learning, with participants developing and increasingly using an effective working relationship with their peers in engaging with cognitive content leading to the construction and confirmation of meaning.

\section{Deepening Understanding: The Influence linking TP with CP}

It is our hope that any learning developed through a Community of Inquiry Framework experience will extend to the higher levels of the cognitive taxonomy, which comprises depth of understanding and the consequent exercise of higher level abilities. We expect such outcomes to call for autonomous efforts by the Community to pursue outcomes which they have come to see as important and valuable. In so doing, they will undoubtedly monitor and regulate their learning; however, more than that is necessary. In their pursuit of deep learning, they will need to be evaluative, critical thinking, and creative problem-solvers. This will depend upon the persistent engagement of TP with the deeper substance of CP (Peacock \& Hooper, 2007). Garrison named the overlap of TP and CP as "Monitoring and Regulating Learning" (2011, p. 23) and described it as bringing TP together with CP, by addressing how learners should interact in activities generally initiated by their teacher. We prefer the more searching concept of "deepening understandings" as a title, since we consider the major contribution of the proactive interaction of $\mathrm{TP}$ and $\mathrm{CP}$ to be the worthwhile deepening of the accumulating understandings that are developing in SP and CP. Such deepening covers the subject matter in hand, and also the ongoing use and development of the abilities, cognitive and interpersonal, that facilitate such learning, individually and within the community.

We therefore regard the facilitative tutors' most significant contribution to the learners' educational experience as initiating their searching and constructive engagement with potentially useful cognitive content. Tutors start and sustain purposeful, critical discourse through collaborative, task-based activities. During such interactions, tutors challenge, probe, and test, while influencing learners' as they share their emergent understandings and develop evidence-based reasoning and emerging concepts. Tutors may support progress by providing examples of critical thinking that demonstrate wider conceptualising in the subject specialism.

This Influence should thus concentrate Tutorial Presence on engaging learners' activity in CP to wholeheartedly progress in deepening engagement with the cognitive goals and content of the programme. The successful impact of this Influence naturally calls for the supportive exercise of an increasingly active responsibility within SP.

\section{Interlinking the Influences}


In the section above we have concentrated upon the interweaving of the Presences in pairs. However, the interlocking of all three significant Presences influences the online educational experience that the CoIF hopes to generate. We envisage these as binding the Presences and the online educational experience together. This suggestion echoes the words of Xin (2012) who reminds her readers that the Presences are an analytic abstraction of parts of the "real thing," similar to a rainbow. She continues:

The frequencies of the light in a rainbow are on a continuum; any attempt to name specific colours of the light misrepresents [of] the thing. That being said, the colors have their function. They provide a way of describing the rainbow and locating different areas within it. In online forums, the social, teaching and cognitive aspects are mingled together in a continuous flow. (Xin, 2012, p. 2)

Thus we suggest that Community of Inquiry tutors should plan, act, and formatively evaluate in terms of interwoven, and not individual, Presences, since it is through these combined engagements that the learners' educational experiences are influenced.

\section{Learner and Tutor Benefits of the Influences}

We have suggested the Influences may:

- ease learner transition into the new, online learning environment, and reduce learner isolation (TP/SP);

- extend learners' notions and awareness of the role of critical thinking, inquiry, dialogue, and reflection in their learning as individuals and as members of a Community (SP/CP);

- improve learners' understandings of, and skills in, social communications (SP/CP);

- encourage the group and individuals to engage trustingly in their self-regulatory and metacognitive activities, including the management of their particular emotional responses to collaborative learning (TP/SP); and

- $\quad$ nurture deep learning (TP/CP).

The Influences offer a more holistic and dynamic Framework for tutors' thinking and planning for online learning. Specifically, they:

- address concerns about fostering deep learning in online environments (CP/TP);

- promote a balanced, but ongoing role for SP supporting CP (SP/CP); and

- inform the development of cognitive maps (CP/TP).

\section{Conclusion}


The purpose of this article has been to present enhancements to the CoIF which are decidedly constructive, making it “. . increasingly fruitful in describing and explaining online learning” (Shea et al., 2012, p. 94), and addressing many of the well-documented challenges of online learning for both learners and tutors. We have found that the Presences, as described in the literature, seem more meaningful and influential for learning when they are interlinked strategically as we have described, in terms of their several Influences on the educational experience, and especially in addressing notable issues identified in current research about online learning and extending its reach and influence. We have summarised a comparison of what both perspectives can offer, in the appendix to this paper. We leave it to readers to make the comparison between concentration on Presences or Influences in assuring the educational experience which is at the heart of the Community of Inquiry Framework.

\section{References}

Akyol, Z. (2013). Metacognitive Development within the Community of Inquiry. In Z. Akyol, \& D. Garrison, Educational Communities of Inquiry: theoretical framework, research and practice (pp. 30-44). Hershey: IGI Global.

Akyol, Z., \& Garrison, D. (2011). Assessing metacognition in an online community of inquiry. The Internet and Higher Education, 23(2), 183-190.

Allen, E., \& Seaman, J. (2013). Changing course: ten years of tracking online education in the United States. Babson Survey Research Group. Retrieved from http://www.onlinelingsurvey.com/reports/changingcourse.pdf

American Public University System. (n.d.). Retrieved from http://www.apus.edu/cti/faculty/community-of-inquiry/

Baxter, J. (2012). Who am I and what keeps me going? Profiling the distance learning student in higher education. International Review of Research in Open and Distance Learning, 13(4), 108-129.

Brindley, J., Blashke, L., \& Walti, C. (2009). Creating effective collaborative learning groups in an online environment. The International Review of Research in Open and Distance Learning, 1O(3). Retrieved from http://www.irrodl.org/index.php/irrodl/article/view/675/1271

Brookfield, S. (1990). The Skilful Teacher. San Francisco: Jossey Bass. Retrieved from http://www.bbc.co.uk/gardening/basics/tecniques/soil makecompost1.shtml

Brown, M. (2015). Stories from students in their first semester of distance learning. International Review of Research in Open and Distributed Learning, 16(4), 1-17.

Capdeferro, N., \& Romero, M. (2012). Are online learners frustrated with collaborative learning experiences? International Review of Research in Open and Distance Learning, 13(2). Retrieved from http://www.irrodl.org/index.php/irrodl/article/view/1127/2129 
Cleveland-Innes, \& Campbell, P. (2012). Emotional presence, learning, and the online learning environment. The International Review of Research in Open and Distance Learning, 13(4), 269-292. Retrieved from http://www.irrodl.org/index.php/irrodl/article/view/1234/2333

Cleveland-Innes, M., Garrison, R., \& Kinsel, E. (2007). Role adjustment for learners in an online community of inquiry: Identifying the challenges of incoming online learners. International Journal of Web-Based Learning and Teaching Technologies, 2(1), 1-9, 11-16.

Columbaro, N., \& Monaghan, C. (2009). Employer Perceptions of Online Degrees: A Literature review. Online Journal of Distance Learning Administration, 12 (1).

Cowan, J. (2006). On Becoming an Innovative University Teacher (2nd edition). Maidenhead, UK: Open University Press.

Cowan, J. (2013, March). Facilitating reflective journalling: reflections on three decades of practice:. Journal of Learning Development in Higher Education, 5.

Cowan, J. (2015). Promoting self-efficacy through affective feedback and feedforward. Journal of Learning and Development in Higher Education, 9.

Dron, J., \& Anderson, T. (2014). Teaching crowds. Edmonton: AU Press, Athabasca University.

Francis, H., \& Cowan, J. (2008). Fostering an action-research dynamic amongst student practitioners. Journal of European Industrial Training, 32(5), 336-346.

Garrison, D. (2011). E-learning in the 21st century: a framework for research and practice. 2nd ed. New York: Routledge.

Garrison, D. (2013). Theoretical foundations and epistemological insights of the community of inquiry. In Z. Akyol, \& D. Garrison, Educational Communities of Inquiry: theoretical framework, researcch and practice (pp. 1-11). Hershey: IGI-Global.

Garrison, D., \& Akyol, Z. (2013). The Community of Inquiry theoretical framework. In M. Moore, Introducing the 2013 Handbook of Distance Education, 3rd edition (pp. 104-120). Abingdon: Routledge.

Garrison, D., Anderson, T., \& Archer, W. (2001). Critical thinking, Cognitive Presence, and computer conferencing in distance education. American Journal of Distance Education, 15(1), 7-23.

Garrison, D., Anderson, T., \& Archer, W. (2010). The first decade of the Community of Inquiry Framework. The Internet and Higher Education, 13(1), 5-9.

Goold, A., Craig, A., \& Coldwell, J. (n.d.). The student experience of working in teams online. Melbourne: Ascilite.

Harasim, L. (2012). Learning theory and online technologies. New York: Routledge. 
Järvenoja, H., \& Järvela, S. (2009). Emotion control in collaborative leanrnng situations; Do students regulate emotions evoked by social challenges? British Journal of Educational Psychology, 79(3), 463-481.

Ke, F. (2010). Examining online teaching, cognitive, and social presence for adult students. Computers \& Education, 55(2), 808-820.

Kehrwald, B. (2008). Understanding social presence in text-based online learning environments. Distance Education, 29(1), 89-106.

Li, L., Chen, G., \& Yang, S. (2013). Construction of cognitive maps to improve e-book reading and navigation. . 6o(1), 32-39.

Lipman, M. (2003). Thinking in education (2nd edition). Cambridge: Cambridge University Press.

McCormick, B., \& Davenport, D. (2004). Shepherd leadership: Wisdom for leaders from Psalm 23 (Y.C. Geh, Trans). Taipei: Apocalypse Press.

Nicholl, T. (1998). Vygotsky. Retrieved from http://www.massey.ac.nz/ alock/virtual/trishvyg.htm

O'Shea, S., Stone, C., \& Delahunty, J. (2015). "I 'feel' like I am at unviersity even though I am online." exploring how students narrate their engagement with higher education institutions in an online learning environment. Distance Education, 36(1), 41-58.

Parkes, M., Stein, S., \& Reading, C. (2015). Student preparedness for university e-learning environments. The Internet and Higher Education, 25(4), 1-10.

Peacock, S. (2015). A constructive, conceptual analytical review of the Community of Inquiry Framework. PhD Thesis ed. University of Stirling. Retrieved from http://dspace.stir.ac.uk/handle/1893/22319

Peacock, S., \& Hooper, J. (2007, September). E-learning in physiotherapy education. Physiotherapy, 93(3), 218-228.

Peacock, S., Morss, K., Scott, A., Hislop, J., Irvine, L., Murray, S., \& Girdler, S. (2010). Using ePortfolios in higher education to encourage learner reflection and support personalised learning. In J. O'Donoghue, Technology-supported environments for personalized learning: methods and case studies (pp. 185-211). New York: Information Science Reference.

Rogers, C. (1980). A Way of Being. Boston, USA: Houghton Mifflin.

Rovai, A. (2002). Sense of community, perceived cogntive learning, and persistence in asynchronous learning networks. The Internet and Higher Education, 5(4), 319-322.

Salmon, G. (2006). E-tivities: The key to active online learning. London: Routledge.

Sfard, A. (1998). On two metaphors for learning and the dangers of choosing just one. Educational Researcher, 27(2), 4-13. 
Shea, P., \& Bidjerano, T. (2009a). Cognitive presence and online learning engagement: A cluster analysis of the community of inquiry framework. Journal of Computing in Higher Education, 21(3), 199-217.

Shea, P., \& Bidjerano, T. (2009b). Community of inquiry as a theoretical framework to foster 'epistemic engagement' and 'cognitive presence' in online education. Computers \& Education, 52(3), 543-553.

Shea, P., Hayes, S., Uzuner-Smith, S., Vickers, J., Bidjerano, T., Gozza-Cohen, M., \& Jian, S. (2012). Learning Presence: Additional research on a new conceptual element within the Community of Inquiry (CoI) Framework. The Internet and Higher Education, 15(2), 89-95.

Shea, P., Hayes, S., Uzuner-Smith, S., Vickers, J. B., Gozza-Cohen, M., Jian, S., \& Tseng, C. (2013, July). Online learner self-regulation: learning presence viewed through quantitative content and social network analysis. The International Review of Research in Open and Distance Learning, 14(3), 427-461. Retrieved from http://www.irrodl.org/index.php/irrodl/article/view/1466/2585

Swan, K., \& Shih, L. (2005). On the nature and development of social presence in online course discussions. Journal of Asynchronous Learning Networks, 9(3), 115-136.

Tolman, E. (1958). Cognitive maps in rats and men. Psychological Review, 55, 189-208.

Vygotsky, L. (1978). Mind in Society. Cambridge, MA: Harvard University Press.

Xin, C. (2012). A Critique of the Community of Inquiry Framework. Journal of Distance Education, 26(1), 1-15.

Xu, J., Du, J., \& Fan, X. (2013). Individual and group-level factors for students' emotion management in online collaborative group. The Internet and Higher Education, 19, 1-9.

\section{Appendix}

\section{Comparison of Behaviours in Presences and Influences}

\begin{tabular}{|l|c|}
\hline \multicolumn{1}{|c|}{ In Presences (Garrison, 2011) } & \multicolumn{1}{c|}{ In Influences (this paper) } \\
$\begin{array}{l}\text { Within a "teacher-guided, non-authoritarian } \\
\text { community" (p.21) }\end{array}$ & $\begin{array}{c}\text { Student-managed learning activity supported by } \\
\text { tutoring and facilitation }\end{array}$ \\
$\begin{array}{l}\text { This is a learning-centred approach rather than a } \\
\text { learner-centred approach (p.54) }\end{array}$ & \\
\hline
\end{tabular}


In SP, Learners:

- Perceive participation in online discussions as a core component of the program of studies (p.103)

Tutors:

- Assess qualitatively the nature of the discourse and then proactively shape it following the critical thinking cycle (p.53)

- Identify areas of agreement/disagreement (p.58)

- Seek to reach consensus/understanding (p.58)

- Confront disruptive individuals directly (p.97)
In TP/SP

Learners:

- feel safe and comfortable in dialogic debates and open exchanges

- develop a trusting sense of belonging

- identify with the group, building trust

- empathically project their personal characteristics into their joint pursuit of worthwhile learning outcomes

- develop coping mechanisms

Tutors:

- Nurture self-efficacy to lead individuals and communities into their ZPD

- Nurture the ongoing development of learners' skills and inclination to project SP

- Encourage learners to use available cognitive maps, record progress, and construct further maps

- Prepare learners to cope with emotion issues

In SP/CP, Learners:

- Work together interdependently

- Ask probing, challenging questions

- Jointly manage opportunities for, and impediments to, cognition

- Review progress to date

- Monitor co-cognition

- Select and set appropriate challenging goals

- Review proposed plans, strategies and potential barriers

- Locate progress to date and inform potential pathways forward

- Share perceived impact of group work on meaning making

- Probe for understanding and misconceptions as well as modelling the critical thinking process (pp.47, 48)

- Most often oblige students to look deeper into a topic by direct instruction (p.98)

- Identify the ideas and concepts worthy of study, provide the conceptual order, organize learning activities, guide the discourse, offer additional sources of information, diagnose misconceptions and interject when required (p.6o)

\section{In TP, Learners:}

- Very much value teaching presence but must also be comfortable questioning or even challenging direct instruction (p.97).

Tutors:

- Ever-present and key persons, managing and monitoring the process... if it is to be more than an informal or fortuitous learning experience (p.83)

- Move the discussion and individual cognitive development through each of the phases of
Tutors:

- Prompt to promote cognition, metacognition, and reflection within postings other's ideas
- Encourage peer's questioning and defense of

\section{In TP/CP, Learners:}

- Monitor and regulate learning

- Evaluate, engage in critical thinking, creativity, and problem-solving

- Deepen accumulating understandings

- Share emergent understandings and develop evidence-based reasoning and emerging concepts

- Wholeheartedly progress in deepening engagement with cognitive goals and content of the programme 


\begin{tabular}{|l|l|}
\hline practical inquiry & \\
- Model critical discourse while shaping the & Tutors: \\
discussion to achieve purposeful goals (p.53) & - Initiate searching and engagement with \\
- Make connections, inject new ideas or concepts, & potentially useful cognitive content \\
construct frameworks, diagnose & - Start and sustain critical discourse \\
misconceptions, focus and resolve issues (p.25) & - Challenge, probe, and test \\
and review and summarize (p.94) & - Call for autonomous efforts to pursue higher \\
- Approach direct instruction (p.25) with the & level outcomes \\
intent of taking learners to higher levels of & - Persistently engage with deeper substance of \\
cognitive development than they might have & CP \\
otherwise reached if they had operated & - Provide examples of critical thinking that \\
independently (p.98) & demonstrate wider conceptualising \\
- Use assessment techniques strategically to & \\
motivate learners (p.102) & \\
- Produce higher order critical thinking in & \\
student discussions by specific instructional & \\
techniques (p.48) & \\
- Encourage appropriate and relevant responses & \\
to bring attention to well-reasoned responses & \\
and make linkages to other messages (p.58) & \\
\end{tabular}

Athabasca

University

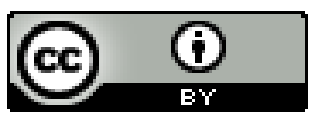

